\title{
Congenital Disorder of Glycosylation Type Id: Clinical Phenotype, Molecular Analysis, Prenatal Diagnosis, and Glycosylation of Fetal Proteins
}

\author{
JONAS DENECKE, CHRISTIAN KRANZ, JUERGEN CH. VON KLEIST-RETZOW, KRISTIN BOSSE, \\ PETER HERKENRATH, OTFRIED DEBUS, ERIK HARMS, AND THORSTEN MARQUARDT
}

Department of Pediatrics [J.D., C.K., O.D., E.H., T.M.], University Hospital of Münster, 48149 Münster, Germany; Department of Pediatrics [J.C.v.K.R., P.H.], University of Cologne, 50924 Cologne, Germany; and Institute of Genetics [K.B.], University of Bonn, 53105 Bonn, Germany

\begin{abstract}
Congenital disorder of glycosylation type Id is an inherited
glycosylation disorder based on a defect of the first mannosyl-
transferase involved in N-glycan biosynthesis inside the endo-
plasmic reticulum. Only one patient with this disease has been
described until now. In this article, a second patient and an
affected fetus are described. The patient showed abnormal gly-
cosylation of several plasma proteins as demonstrated by iso-
electric focusing and Western blot. Lipid-linked oligosaccharides
in the endoplasmic reticulum, reflecting early N-glycan assem-
bly, revealed an accumulation of immature Man ${ }_{5}$ GlcNAc ${ }_{2}^{-}$
glycans in fibroblasts of the patient. Chorion cells of the affected
fetus showed the same characteristic lipid-linked oligosaccha-
rides pattern. However, the fetus had a normal glycosylation of
\end{abstract}
several plasma proteins. Some fetal glycoproteins are known to be derived from the mother, but even glycoproteins that do not cross the placenta were normally glycosylated in the affected fetus. Maternal or placental factors that partially compensate for the glycosylation defect in the fetal stage must be proposed and may be relevant for the therapy of these disorders in the future. (Pediatr Res 58: 248-253, 2005)
Abbreviations
CDG, congenital disorder of glycosylation
IEF, isoelectric focusing
LLO, lipid-linked oligosaccharides

Inherited defects that affect the biosynthesis of $\mathrm{N}$ - or $\mathrm{O}$-glycans are named congenital disorders of glycosylation (CDG) (1). N-linked glycans are attached to asparagine residues of the protein when the Asn occurs within the consensus sequence Asn-X-Ser/Thr. A precursor glycan $\left(\mathrm{Glc}_{3} \mathrm{Man}_{9} \mathrm{GlcNAc}_{2}\right)$ is first assembled in the endoplasmic reticulum on a lipid (dolichol) anchor via a pyrophosphate linkage $\left(\mathrm{Glc}_{3} \mathrm{Man}_{9} \mathrm{GlcNAc}_{2}-\mathrm{PP}\right.$-dolichol). The glycan is transferred from the anchor to nascent protein and is processed further in the endoplasmic reticulum and Golgi apparatus. O-glycans are attached to serine or threonine residues of the protein via a GalNAc- $\alpha$-Ser/Thr linkage and are elongated one sugar at a time; this process occurs in the endoplasmic reticulum and Golgi apparatus. The biochemical compartmentation of the assembly of $\mathrm{N}$ - and O-glycans

Received July 7, 2004; accepted November 18, 2004

Correspondence: Jonas Denecke, M.D., Department of Pediatrics, Albert-SchweitzerStr. 33, 48149 Münster, Germany; e-mail: deneckj@uni-muenster.de.

This work was supported by a grant of Innovative Medizinische Forschung (IMF De110325).

DOI: 10.1203/01.PDR.0000169963.94378.B6 gave rise to the classification of CDG into two subgroups, type I affecting the assembly of the precursor $\mathrm{N}$-glycans on the lipid anchor in the endoplasmic reticulum and type II affecting the processing of the $\mathrm{N}$-glycan after transfer to the protein (2). In recent years, 17 different CDG were characterized, and recently disorders of $\mathrm{N}$ - or O-glycosylation that are not yet part of the CDG nomenclature were described (3-5).

In 1995, Stibler et al. (6) described two patients with severe psychomotor retardation and an abnormal isoelectric focusing (IEF) pattern of transferrin, suspecting a new subtype of CDG. The biochemical and molecular defect of one patient could subsequently be elucidated by Körner et al. (7), who found a defect in the assembly of lipid-linked oligosaccharides (LLO) in the endoplasmic reticulum of the patient with an accumulation of $\mathrm{Man}_{5} \mathrm{GlcNAc}_{2}$-PP-dolichol. A missense mutation in the human ALG3 gene (8) (synonym: NOT56L, neighbor of tumorous imaginal discs-like protein) coding for dolichyl-PMan:Man5GlcNAc2-PP-dolichyl mannosyltransferase (EC 2.4.1.131) could be demonstrated (7). Up to now, only this one patient with CDG Id has been described, and the clinical spectrum of the disease is not well defined. The clinical 
symptoms of CDG Id and the symptoms of the clinically very similar disorder CDG Ie are listed in Table 1.

We describe a new patient and a fetus affected by CDG Id. IEF of transferrin and Western blots of serum proteins were performed. LLO analysis of fibroblasts of the patient and of chorion cells of the affected fetus revealed the presence of truncated LLO. Genomic sequencing of the ALG3 gene confirmed the diagnosis of CDG Id. Because a mutation that affected splicing was found, expression studies of the $A L G 3$ gene using real-time PCR were performed to prove the physiologic significance of the mutation.

\section{METHODS}

IEF, SDS-PAGE, and Western blot. IEF of serum transferrin was performed with a PHAST electrophoresis system using a gel with a $\mathrm{pH}$ range of 5-7 (Pharmacia, Freiburg, Germany). Transferrin was immunoprecipitated and stained as described previously (9).

Serum proteins were separated on 7.5 or $10 \%$ SDS polyacrylamide gels under reducing conditions and transferred to a PVDF membrane by Western blotting using standard procedures. After the membrane was blocked in $1 \%$ blocking solution (Boehringer, Mannheim, Germany) at $4^{\circ} \mathrm{C}$ overnight, it was incubated with polyclonal antibodies (1:5000) for $\alpha 1$-antitrypsin, antithrombin III, or $\alpha 1$-acid glycoprotein (Dako, Hamburg, Germany) for $1 \mathrm{~h}$ and washed three times in Tris-buffered saline with Tween $200.1 \%$ (pH 7.5). Blots were incubated with a peroxidase-conjugated secondary goat anti-rabbit antibody (Dako) for $30 \mathrm{~min}$ (1:2500). After washing in TBS, visualization of the protein bands was performed using a Chemiluminescence Blotting Substrate Kit (Hoffmann-La Roche Ltd, Basel, Switzerland).

Deglycosylation of plasma proteins. N-glycans were enzymatically released from total plasma proteins by incubation of $1 \mu \mathrm{L}$ of plasma with PNGaseF (NEB, Frankfurt, Germany) for $5 \mathrm{~h}$. Subsequently, proteins were precipitated using ice-cold ethanol and air dried, and SDS electrophoresis buffer was added. Protein detection on Western blot was performed as described above.

Analysis of LLO. Chorion cells of the fetus and of a healthy control subject as well as dermal fibroblasts of the patient with CDG Id and a control subject were metabolically labeled with $100 \mu \mathrm{Ci}\left[2-{ }^{3} \mathrm{H}\right]$ mannose per milliliter of labeling medium for $30 \mathrm{~min}$ and chased for $10 \mathrm{~min}$ in MEM. Oligosaccharides linked to dolichol were released, extracted, and analyzed by HPLC as described previously (10). In brief, cells were harvested and extracted in chloroform/methanol 2:1 three times. The extract was dried under nitrogen and extracted with water. Subsequently, an extraction with chloroform/methanol/ water 10:10:3 was performed, and LLO were released from dolichol by mild acid hydrolysis for $20 \mathrm{~min}$ at $100^{\circ} \mathrm{C}$ in n-propanolol/0.1 N HCl (1:2). Glycans were detected by HPLC (Waters Alliance System; Waters, Eschborn, Germany) in an acetonitrile/water gradient using a Microsorb MV column (Varian,
Darmstadt, Germany). For the identification of the peaks, commercially available fluorescence standards were used (Takara, Otsu, Shiga, Japan).

$\boldsymbol{P C R}$. Genomic DNA was prepared from whole blood, fibroblasts, or chorion cells using a commercially available kit (Qiagen, Hilden, Germany). Genomic sequencing and direct sequencing of cDNA were performed using the primers described previously (11). The samples were cycled 35 times using different conditions for amplification (protocols are available upon request).

Reverse transcription. RNA of chorion cells was extracted using a commercially available kit (RNeasy; Qiagen). RNA was quantified spectrophotometrically, and $1 \mu \mathrm{g}$ of total RNA was used for reverse transcription (firststrand cDNA synthesis kit; Roche, Mannheim, Germany) according to the manufacturer's instructions. cDNA was stored at $-30^{\circ} \mathrm{C}$ until use.

Sequence analysis. DNA and cDNA were sequenced using an automated DNA sequencer (Applied Biosystems, Weiterstadt, Germany) and standard procedures.

Real-time PCR. Primers and PCR conditions used for real-time PCR of the $A L G 3$ transcripts were described in detail previously (11). In brief, real-time PCR was performed using the QuantiTect SYBR Green PCR Master Mix (Qiagen) with a real-time PCR cycler (ABI PRISM 7900HT Sequence Detection System; Applied Biosystems Foster City, CA). The primers spanned either the normal exon $1 /$ exon 2 boundary or the truncated exon1del/exon 2 boundary, thus exclusively amplifying either the normal transcript or the transcript carrying the deletion. One microgram of RNA was used for reverse transcription using random primers, and $10 \mathrm{ng}$ of cDNA was applied. Each sample was cycled in duplicate.

The presence of primer dimers and unspecific PCR products was excluded by determination of the melting curve. 18S rRNA was used to normalize the samples for differences in the applied quantity of RNA and variations in cDNA synthesis efficiency. For amplification, TaqMan Universal PCR Master Mix and the predeveloped human $18 \mathrm{~S}$ rRNA assay were used (Applied Biosystems).

The ABI Prism SDS 2.0 software (Applied Biosystems) was used to determine the cycle threshold (ct) for the samples. Relative amounts of copies were calculated by comparing their ct values according to Livak et al. (12). Informed consent was obtained from all participants, and the study was approved by the Institutional Review Board.

\section{RESULTS}

Clinical phenotype. The patient is a 6-y-old boy of Italian origin. His parents come from a small village in Sicily, where both families have lived for generations but were not known to be consanguineous. The family history is uneventful. After a normal pregnancy, the boy was born at $39+3$ wk with a body length of $48 \mathrm{~cm}$ (50th percentile), body weight of $4700 \mathrm{~g}$ $(>97$ th percentile), and head circumference of $36 \mathrm{~cm}$ (75th percentile). Arthrogryposis multiplex was present at birth,

Table 1. Major clinical symptoms of CDG Id and CDG Ie

\begin{tabular}{lll}
\hline & \multicolumn{1}{c}{ CDG Id (2) } & CDG Ie (5) \\
\hline Muscular tone & Hyper-/Hypotonia (2) & Hypotonia (5) \\
Contractures & $n(1)-++(1)$ & $n(1)-++(2)($ nd 2) \\
Deep tendon reflexes & $n(2)$ & $n(2)-++(1)($ nd 2) \\
Nerve conduction & $n(2)$ & $n(1)-$ reduced (1)(nd 3) \\
Seizures & $+++(2)$ & $+++(5)$ \\
Psychomotor development & Severely impaired (2) & Severely impaired (5) \\
Facial dysmorphism & $+(2)$ & $n(1)-+(4)$ \\
Microcephaly &,+++ normal at birth (2) & ++ normal at birth (5) \\
Vision/Ophthalmology & Optic atrophy (2), coloboma (1) & Optic atrophy (1)(nd 4), Cortical blindness (4) \\
MRI of the CNS & Brain atrophy (2) & delayed myelination (5), mild cerebral hypoplasia, \\
& & cerebellar atrophy (inconstant) (4) \\
Failure to thrive & $++(2)$ & $n(1)-++(2)$ (nd 2) \\
Antithrombin & Reduced (2) & Reduced (4)(nd 1) \\
Electroretinogram & reduced amplitude (1)(nd 1) & $n$ (1) - reduced amplitude (1)(nd 3) \\
Elevated creatine kinase & $n(2)$ & $+-+++(5)$ \\
\hline
\end{tabular}

$n$, normal; nd, not determined or not reported.

+ to +++ grade of symptoms.

Number of patients showing specific symptoms in parentheses. 
including clubfeet and contractures of the hands. At the end of the first month of life, recurrent vomiting occurred and hypertrophy of the pyloric muscle was diagnosed. A muscle biopsy at 2 mo of age showed moderate fibrosis and hypertrophy of type $2 \mathrm{c}$ muscle. Starting at 2 mo of age, abnormal EEG recordings that initially showed a burst-suppression pattern were obtained. The patient was put on anticonvulsive treatment, starting with phenobarbital and later changed to vigabatrin even before the first seizures were clinically apparent. At 4 mo of age, the first episode of epileptic seizures was triggered by fever, followed by another one 4 mo later. The patient received a diagnosis of West syndrome and became seizurefree by treatment with valproate during his second year of life. Seizures resumed recently at the age of $5 \mathrm{y}$ and are currently not controlled any more by valproate. Magnetic resonance imaging scans of the brain at 6 mo of age revealed cerebral atrophy (Fig. 1). Hearing tests showed no abnormalities.

At $6 \mathrm{y}$ of age, the patient has severe vision impairment. He is unable to fixate on objects or to recognize them. He reacts to light. An electroretinography at 6 mo of age showed reduced amplitudes. The boy is unable to sit without support but can actively turn from back to front. He gropes for his toys and shows recognition when he touches them. There is no speech development. At $5 \mathrm{y}$ of age, his body height was $98 \mathrm{~cm}$ (3rd percentile), his weight was $14.1 \mathrm{~kg}$ (3rd percentile), and his head circumference was $46.3 \mathrm{~cm}(<3 \mathrm{rd}$ percentile). There is little s.c. fat. The nasal bridge is broad and flat. The frontal teeth are close to each other, whereas wide spaces are present between the other teeth. The palate has a normal curving. There is no hepatosplenomegaly. Bilateral maldescensus testis is present. Patellar tendon reflexes are present, and Babinski sign is negative. Motor nerve conduction velocities are normal. The eyes show abnormal rotational and horizontal movements; light reaction of the pupils is present. There are contractures and clinodactyly of the distal phalanges of the fifth digits of the hands. A simian crease is present at the right palm. Nails of the second and third digits of the hands are small and dysplastic, and the fingers show a conical narrowing toward their ends. There are no feeding problems. Laboratory tests revealed normal values for plasma creatinine, liver transaminases, alkaline phosphatase, thyroid hormones, and urinary organic acids. Figure 1 shows pictures of the patient and some of the described physical stigmata at $5 \mathrm{y}$ of age. Additional pictures and a movie of the patient can be found at our web site (http://cdg.uni-muenster.de).

IEF, SDS-PAGE, and Western blots. The mobility of transferrin separated by IEF depends on the amount of negatively charged terminal sialic acids of the oligosaccharide chains. Normally, two N-linked oligosaccharides each carrying two sialic acids are present on transferrin. IEF of the CDG Id patients revealed an additional band at the position of disialotransferrin. A shift of the apparent molecular weight of $\sim 2 \mathrm{kD}$ in SDS-PAGE, the mass of one oligosaccharide chain, indicates the lack of at least one of the two complete oligosaccharides normally attached to transferrin (Fig. 2). Analysis of $\alpha 1$-antitrypsin, antithrombin III, and $\alpha 1$-acid glycoprotein demonstrated the glycosylation defect for other glycoproteins as well (Fig. 2).
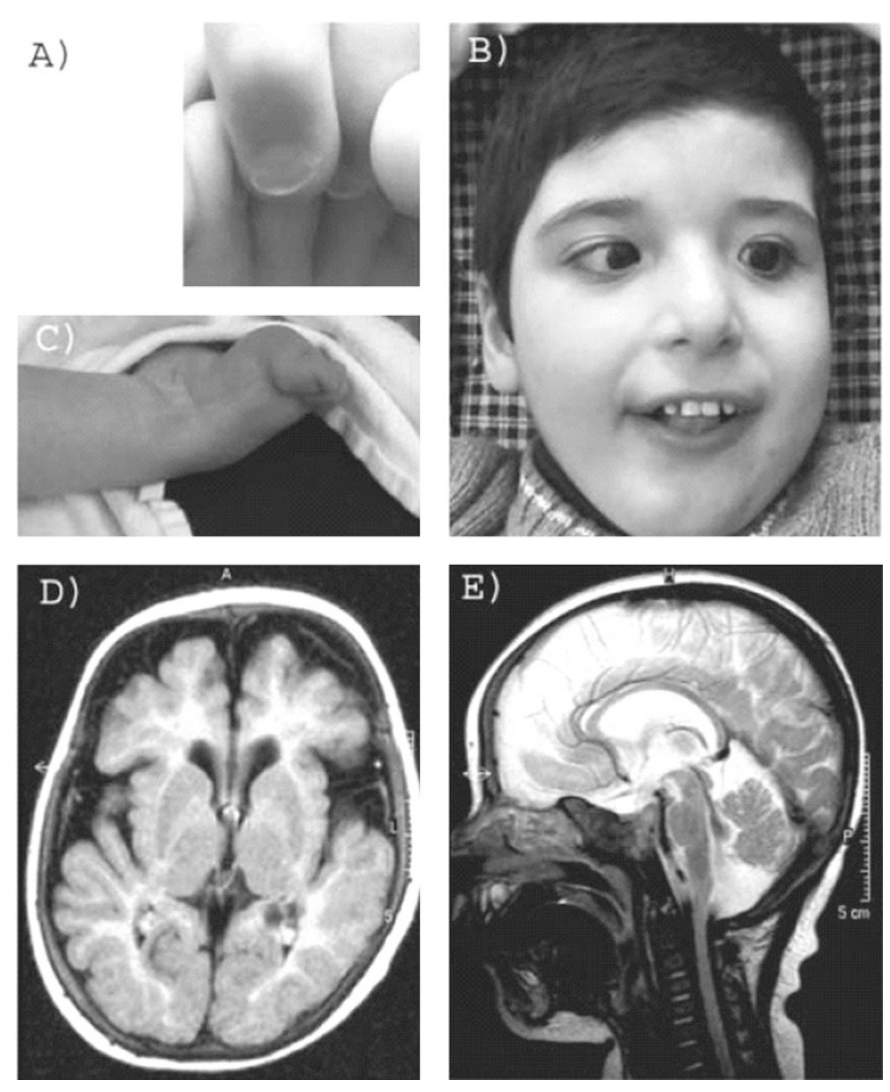

Figure 1. Clinical pictures of the patient with CDG Id at the age of $5 \mathrm{y}$. Dysplastic nails at both hands $(A)$ and club feet $(C)$ are present. Strabismus convergens, epicanthus, and a broad nose bridge are features of the patients face $(B)$. MRT of the brain revealed a generalized, frontal accentuated brain atrophy $(D)$, whereas the cerebellum is normal $(E)$.

Transferrin of an affected fetus (19 wk gestational age), sibling of the patient and likewise carrying the mutations in the Not56 gene, showed no obvious glycosylation abnormalities in the IEF and SDS-PAGE of transferrin (Fig. 2). Because transferrin is known to partially cross the placenta from mother to fetus, Western blots of $\alpha 1$-antitrypsin, $\alpha 1$-acid glycoprotein, and antithrombin III were performed (Fig. 3). Whereas the former two proteins revealed no glycosylation abnormalities in the fetus, the antithrombin III showed two bands indicating hypoglycosylation of the protein, although to a lesser extent than that in the patient with CDG Id (Fig. 3). The enzymatic release of $\mathrm{N}$-glycans from $\alpha 1$-antitrypsin, $\alpha 1$-acid glycoprotein, and antithrombin III by PNGaseF digestion and subsequent Western blotting proved that the protein pattern in Western blots is caused solely by differences in $\mathrm{N}$ glycosylation and not influenced by protein heterogeneity or O-glycans (Fig. 3).

LLO. Investigation of LLO after metabolic labeling was done to find disturbances in the stepwise assembly of the precursor $\mathrm{N}$-glycan of the final structure $\mathrm{Glc}_{3} \mathrm{Man}_{9} \mathrm{GlcNAc}_{2}$ on the lipid anchor dolichol in the endoplasmic reticulum. LLO were size-fractionated and analyzed by HPLC. Fibroblasts of a healthy control subject and the patient with CDG Id, as well as chorion cells of a control and chorion cells of the affected fetus, were investigated (Fig. 4). In normal fibroblasts, the major fractions corresponded to the mature $\mathrm{Glc}_{3} \mathrm{Man}_{9} \mathrm{GlcNAc}_{2}$ gly- 


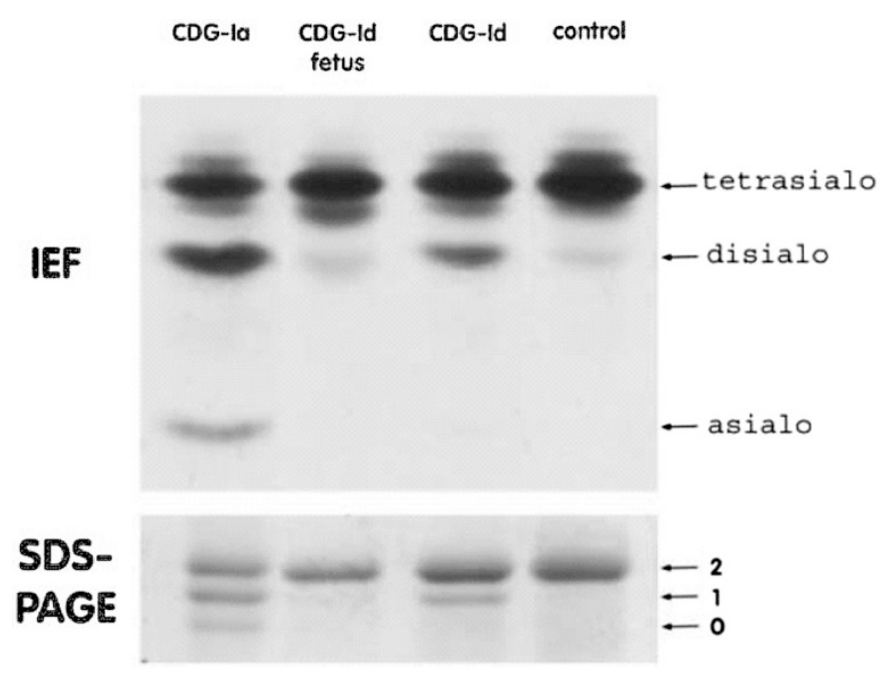

Figure 2. IEF pattern and SDS-PAGE of transferrin of a patient with CDG Ia, the fetus with CDG Id at 19 wk of gestational age, the patient with CDG Id, and a healthy control subject. The arrows on the right indicate tetrasialo-, disialo-, and asialotransferrin in the IEF and transferrin carrying two, one, or no oligosaccharide chains in the SDS-PAGE. Whereas the patient with CDG Id showed normal transferrin and transferrin missing one oligosaccharide chain, the affected fetus showed no abnormalities in transferrin glycosylation.

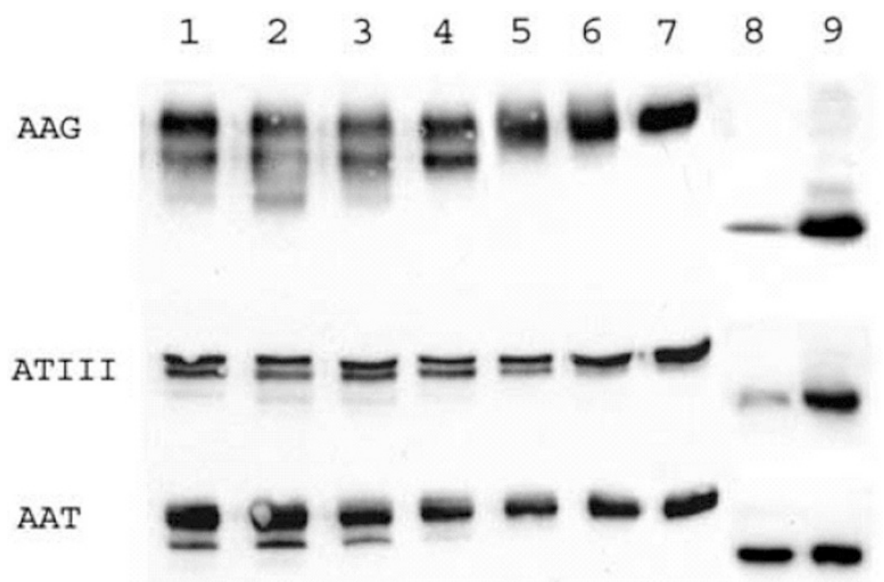

Figure 3. Western blot of whole-plasma proteins probed with antibodies for $\alpha 1$-acid glycoprotein (AAG), antithrombin III (AT III), and $\alpha-1$ antitrypsin (AAT). Lanes 1-3, plasma of patients with CDG Ia; lane 4, plasma of the patient with CDG Id; lane 5, plasma of the fetus with CDG Id at 19 wk of gestational age; lanes 6 and 7, plasma of healthy control subjects; Lanes 8 and 9 , plasma of the fetus and a healthy control subject after enzymatic removal of $\mathrm{N}$-glycans. The upper bands of each blot represent the fully glycosylated proteins with additional bands in patients with CDG representing the deficiency of at least one N-glycan chain. In the affected fetus (lane 5), only AT III shows a hypoglycosylation phenotype, although to a milder extent than the sibling with CDG Id (lane 4).

can and smaller peaks corresponded to the intermediates of the $\mathrm{Glc}_{3} \mathrm{Man}_{9} \mathrm{GlcNAc}_{2}$ synthesis. LLO of the patient with CDG Id showed an accumulation of immature $\mathrm{Man}_{5} \mathrm{GlcNAc}_{2}$ with only small amounts of the mature $\mathrm{Glc}_{3} \mathrm{Man}_{9} \mathrm{GlcNAc}_{2}$ glycan, indicating a disturbed assembly of LLO at the $\mathrm{Man}_{5}$ level.

In control chorion cells, there is an increased amount of $\mathrm{Man}_{9} \mathrm{GlcNAc}_{2}$ glycan intermediate relative to the mature $\mathrm{Glc}_{3} \mathrm{Man}_{9} \mathrm{GlcNAc}_{2}$ glycan when compared with control fibro-

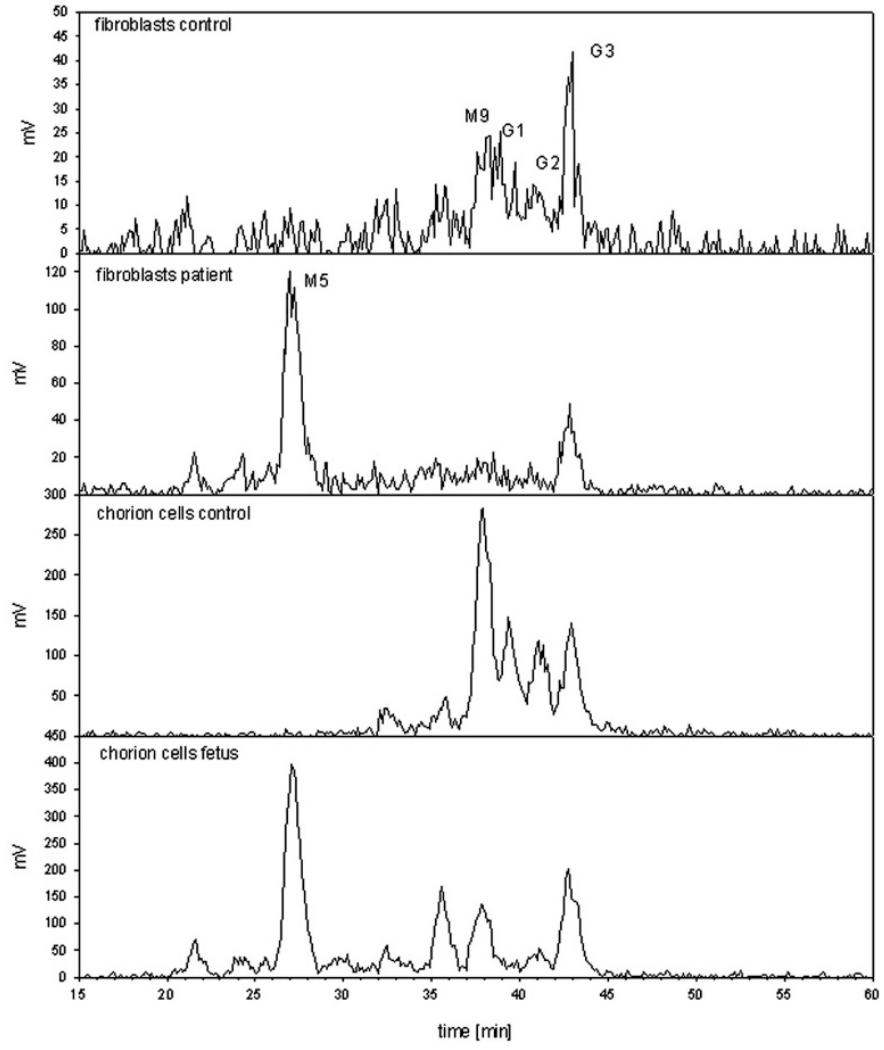

Figure 4. HPLC analysis of LLO in fibroblasts from a healthy control subject and the patient with CDG Id and in chorion cells of a control subject and chorion cells of the affected fetus. Cells were labeled with $\left[{ }^{3} \mathrm{H}\right]$ mannose and $\left[{ }^{3} \mathrm{H}\right]$ oligosaccharides, and LLO were released and fractionated by reversedphase HPLC. Normal fibroblasts showed LLO with a predominant peak at the mature $\mathrm{Glc}_{3} \mathrm{Man}_{5} \mathrm{GlcNAc}_{2}$ structure (above), whereas CDG Id fibroblasts showed predominance of the truncated $\mathrm{Man}_{5} \mathrm{GlcNAc}_{2}$ oligosaccharide. Control chorion cells show more $\mathrm{Man}_{9} \mathrm{GlcNAc}_{2}$ than control fibroblasts, revealing a slower assembly of the mature oligosaccharide but lacking $\mathrm{Man}_{5} \mathrm{GlcNAc}_{2}$ that is predominant in the chorion cells of the affected fetus.

blasts using identical labeling conditions. The chorion cells of the affected fetus revealed a major peak at the $\mathrm{Man}_{5} \mathrm{GlcNAc}_{2}$ position comparable to the patient's fibroblasts, but there were also more mature intermediates of the LLO assembly, indicating that the biochemical defect was present in the fetus but was slightly more leaky in chorion cells of the fetus than in fibroblasts of the patient (Fig. 4).

Molecular investigations. A homozygous mutation in exon 1 of the $A L G 3$ gene of our patient resulted in aberrant splicing and the formation of a transcript that is proposed to code for a nonfunctional enzyme. The molecular findings of the patient described in this report are described in detail elsewhere (11). The ALG3 gene of a fetus, sibling of the patient, was sequenced, and the homozygous mutation g. $165 \mathrm{C}>\mathrm{T}$ (c.del.160-196, p.Val54fsX66) was found, confirming that the fetus was also affected by CDG Id. Using real-time PCR, we found $98.8 \%$ of the $A L G 3$ transcripts with aberrant splicing and only $1.2 \%$ of total $A L G 3$ transcripts coding for the normal, fully active enzyme in the fetus, levels that were similar to the ratio found in fibroblasts and leucocytes of the patient, in whom $99.5 \%$ aberrant spliced ALG3 transcripts and $0.5 \%$ normal transcripts were found. The overall expression levels of 
ALG3 in chorion cells of a healthy fetus and the fetus with CDG Id were identical to those in skin fibroblasts of a healthy control subject and the sibling with CDG Id when compared with the expression of two housekeeping genes (GAPDH and hALU; data not shown).

Because the accumulation of $\mathrm{Man}_{5} \mathrm{GlcNAc}_{2}$ on dolichol is not specific for CDG Id and the clinical picture as well as the LLO phenotype were also compatible with CDG Ie (13-15) (Table 1), we additionally sequenced the DPMI gene and its subunits DPM2 and DPM 3 after RT-PCR of the corresponding transcripts of our patient with CDG Id. A mutation in the coding region of the genes could be ruled out (data not shown).

\section{DISCUSSION}

CDG Id was discovered in 1999, but up to now, only one patient has been identified. The clinical picture had been described earlier by Stibler et al. (6) and was followed by the molecular characterization of the disease by Korner et al. (7). Our patient has severe psychomotor retardation, secondary microcephaly, and seizures in common with the first patient. Additional symptoms include arthrogryposis multiplex present at birth and a severe vision impairment. Unlike the first patient, he has no coloboma of the iris. The clinical phenotype of CDG Id is very similar to the one found in CDG Ie. In fact, many of the symptoms present in the patient described above have been reported to be characteristic for CDG Ie. A comparison of symptoms of these two disorders is summarized in Table 1. As shown by the symptoms listed in Table 1, the distinction of CDG Id and Ie on the basis of clinical symptoms alone may well be impossible. Determination of serum creatine kinase might be helpful to distinguish CDG Id and Ie because it is normal in CDG Id but elevated in CDG Ie.

IEF and SDS-PAGE patterns of serum transferrin were different from CDG Ia. Asialotransferrin, which is commonly found in CDG Ia, was hardly detectable in both patients with CDG Id described so far.

As we could show previously (11), an apparently silent mutation in the patient with CDG Id described here activates a cryptic splice site in exon 1, resulting in an almost exclusive usage of the activated cryptic splice site. The formation of a premature stop codon as a result of a deletion of $37 \mathrm{bp}$ in the $A L G 3$ transcripts implicates a loss-of-function mutation. The genetic background of the different $A L G 3$ transcripts in the newly diagnosed fetus were identical to those described in the patient with CDG Id (11). Even though there were slightly more normal $A L G 3$ transcripts in the fetal chorion cells than in fibroblasts of the patient (1.2\% in the fetus versus $0.5 \%$ in the patient), the amount of normal transcripts coding for the complete ALG3 protein was severely decreased. Accordingly, LLO of chorion cells that carried the mutation showed the metabolic block in the LLO assembly but also were slightly more leaky than LLO of the patient's fibroblasts. Abnormalities in the LLO pattern of chorion cells of a fetus who has CDG Id could be demonstrated here for the first time and suggests the suitability of LLO analysis for the diagnosis of CDG Id and most probably of other CDG type I in affected fetuses.
Plasma glycoproteins were markedly hypoglycosylated in the patient with CDG Id. However, neither transferrin nor $\alpha 1$-AT or $\alpha 1$-acid glycoprotein showed glycosylation abnormalities in the fetus at $19 \mathrm{wk}$ of gestational age, although the LLO pattern as well as the molecular analysis clearly showed the defect in cells of the fetus (Fig. 4). Similar results were obtained by Clayton et al. (16) in a fetus with CDG Ia. To perform prenatal diagnosis from cord blood of a fetus who is suspected to have CDG Ia, IEF of transferrin and $\alpha 1$ antitrypsin of a patient who had CDG Ia at 19 wk gestation was performed and showed normal mobility patterns (16). Nevertheless, the patient turned out to have CDG Ia. Hypoglycosylation of serum proteins was not detectable before the third week of life. Normal glycosylation was not present in all plasma glycoproteins of the CDG Id fetus because antithrombin III revealed hypoglycosylation, although to a lower extent than in the sibling with CDG Id. Antithrombin III carries four $\mathrm{N}$-glycans, and hypoglycosylation of patients with CDG was described to result in at least one additional band of lower molecular weight in SDS page (17). However, $10-15 \%$ of hypoglycosylated antithrombin III, termed $\mathrm{AT} \operatorname{III} \beta$, is even common in healthy individuals (18), and the normal ratio in the fetus is yet unknown. Thus the presence of AT III $\beta$ does not necessarily represent a CDG phenotype.

A plausible explanation for the presence of normally glycosylated serum proteins in CDG Ia and CDG Id is the predominance of maternal proteins in the fetal serum. In fact, some maternal plasma proteins are known to cross the placenta in relevant amounts. IgG levels in neonatal and fetal blood are $\sim 1.5$-fold higher than in the maternal blood as a result of active placental transport (19). There are variable data about the placental transport of transferrin, but although the fetal liver produces transferrin from the ninth week of gestational age, at least some transferrin crosses the placenta from mother to fetus $(20,21)$. However, the placenta is tight for almost all other proteins, and even with high concentration gradients of $>1: 1000$, diffusion levels are low (22,23). $\alpha 1$-Antitrypsin and other proteins that are found to be normally glycosylated in the affected fetus do not cross the placenta in relevant amounts. We conclude that there are factors partially compensating for the defect in the fetus. Expression patterns of glycosyltransferases are widely different during embryogenesis (24-26). Thus, a different expression pattern of enzymes as a result of different developmental regulation of genes contributing to the $\mathrm{N}$-glycan synthesis might partially compensate for the defect in some tissues of the embryo and the fetus. In fact, de Jong et al. (27) could show an increase of hyperglycosylated transferrin in the maternal serum during pregnancy, an effect that could be detected in women who were taking oral contraceptives, too (28), thus pointing to the relevance of hormones for hyperglycosylation. In fact, the genes of several glycosyltransferases contain hormone-responsive elements, nucleotide sequences within the promoter regions that are well conserved (29).

Correction of the glycosylation defect seems to be restricted to glycoproteins synthesized in distinct organs, because in patients with CDG Ia, the CNS shows cerebellar hypoplasia, and fat pads and inverted nipples are already present at birth (16). Because the biochemical origins of CDG Ia, a disorder 
that is based on limited supply of GDP-mannose, and CDG Id, a disorder that affects an LLO assembly step, differ significantly, the basis of this phenomenon remains unclear. Nevertheless, it seems that maternal, fetal, or placental factors might normalize $\mathrm{N}$-glycosylation of plasma proteins during pregnancy in biochemically different glycosylation disorders. In this context, it is important to question whether the gestational age or the time frame after delivery is decisive for the occurrence of hypoglycosylated transferrin in patients with CDG. The patient with CDG Ia described by Clayton et al. (16) was delivered at $35 \mathrm{wk}$ of gestation, and carbohydrate-deficient glycoproteins became detectable in the second to third weeks of postnatal life. The same constellation was found in one of our patients who had CDG Ia and was delivered at 39 wk of gestation (data not shown). According to the half-life time of transferrin of $\sim 8 \mathrm{~d}, 2-3 \mathrm{wk}$ after delivery, relevant amounts of hypoglycosylated transferrin would be expected in the patients with CDG independent of the gestational age if the delivery is decisive for the change of glycosylation. Thus, the limited data available suggest that plasma protein glycosylation is altered at the time of delivery.

We thus propose that the appearance of normally glycosylated plasma proteins is not autonomously regulated by the fetus but at least also by placental or maternal factors such as hormones that are withdrawn at the time of delivery. As an explanation for this phenomenon, developmentally regulated genes in the fetal liver are the most conceivable model. However, there is no enzymatic cascade that is known to be able to bypass the enzymatic block in CDG Ia and Id. Nevertheless, even later on in life, the hypoglycosylation of plasma proteins in patients with CDG Ia can be normal for prolonged periods of time (T.M., personal observation). It is tempting to speculate that this phenomenon might offer a possible approach for the development of therapeutic agents for these disorders.

\section{REFERENCES}

1. Marquardt T, Denecke J 2003 Congenital disorders of glycosylation: review of their molecular bases, clinical presentations and specific therapies. Eur J Pediatr 162:359 379

2. Aebi M, Helenius A, Schenk B, Barone R, Fiumara A, Berger EG, Hennet T, Imbach T, Stutz A, Bjursell C, Uller A, Wahlstrom JG, Briones P, Cardo E, Clayton P, Winchester B, Cormier-Dalre V, de Lonlay P, Cuer M, Dupre T, Seta N, de Koning T, Dorland L, de Loos F, Kupers L, et al. 1999 Carbohydrate-deficient glycoprotein syndromes become congenital disorders of glycosylation: an updated nomenclature for CDG. First International Workshop on CDGS. Glycoconj J 16:669-671

3. Yu LC, Twu YC, Chang CY, Lin M 2001 Molecular basis of the adult I phenotype and the gene responsible for the expression of the human blood group I antigen. Blood 98:3840-3845

4. Beltran-Valero de Bernabe D, Currier S, Steinbrecher A, Celli J, van Beusekom E, van der Zwaag B, Kayserili H, Merlini L, Chitayat D, Dobyns WB, Cormand B, Lehesjoki AE, Cruces J, Voit T, Walsh CA, van Bokhoven H, Brunner HG 2002 Mutations in the O-mannosyltransferase gene POMT1 give rise to the severe neuronal migration disorder Walker-Warburg syndrome. Am J Hum Genet 71:1033-1043

5. Yoshida A, Kobayashi K, Manya H, Taniguchi K, Kano H, Mizuno M, Inazu T, Mitsuhashi H, Takahashi S, Takeuchi M, Herrmann R, Straub V, Talim B, Voit T,
Topaloglu H, Toda T, Endo T 2001 Muscular dystrophy and neuronal migration disorder caused by mutations in a glycosyltransferase, POMGnT1. Dev Cell 1:717-724

6. Stibler H, Stephani U, Kutsch U 1995 Carbohydrate-deficient glycoprotein syndrome - a fourth subtype. Neuropediatrics 26:235-237

7. Korner C, Knauer R, Stephani U, Marquardt T, Lehle L, von Figura K 1999 Carbohydrate deficient glycoprotein syndrome type IV: deficiency of dolichyl-PMan:Man(5)GlcNAc(2)-PP-dolichyl mannosyltransferase. EMBO J 18:6816-6822

8. Aebi M, Gassenhuber J, Domdey H, te Heesen S 1996 Cloning and characterization of the ALG3 gene of Saccharomyces cerevisiae. Glycobiology 6:439-444

9. Niehues R, Hasilik M, Alton G, Korner C, Schiebe-Sukumar M, Koch HG, Zimmer KP, Wu R, Harms E, Reiter K, von Figura K, Freeze HH, Harms HK, Marquardt T 1998 Carbohydrate-deficient glycoprotein syndrome type Ib. Phosphomannose isomerase deficiency and mannose therapy. J Clin Invest 101:1414-1420

10. Kranz C, Denecke J, Lehrman MA, Ray S, Kienz P, Kreissel G, Sagi D, PeterKatalinic J, Freeze HH, Schmid T, Jackowski-Dohrmann S, Harms E, Marquardt T 2001 A mutation in the human MPDU1 gene causes congenital disorder of glycosylation type If (CDG-If). J Clin Invest 108:1613-1619

11. Denecke J, Kranz C, Kemming D, Koch HG, Marquardt T 2004 An activated 5 cryptic splice site in the human ALG3 gene generates a premature termination codon insensitive to nonsense-mediated mRNA decay in a new case of congenital disorder of glycosylation type Id (CDG-Id). Hum Mutat 23:477-486

12. Livak KJ, Schmittgen TD 2001 Analysis of relative gene expression data using real-time quantitative PCR and the 2(-Delta Delta C(T)) method. Methods 25:402408

13. Kim S, Westphal V, Srikrishna G, Mehta DP, Peterson S, Filiano J, Karnes PS, Patterson MC, Freeze HH 2000 Dolichol phosphate mannose synthase (DPM1) mutations define congenital disorder of glycosylation Ie (CDG-Ie). J Clin Invest 105:191-198

14. Imbach T, Schenk B, Schollen E, Burda P, Stutz A, Grunewald S, Bailie NM, King MD, Jaeken J, Matthijs G, Berger EG, Aebi M, Hennet T 2000 Deficiency of dolichol-phosphate-mannose synthase-1 causes congenital disorder of glycosylation type Ie. J Clin Invest 105:233-239

15. Garcia-Silva MT, Matthijs G, Schollen E, Cabrera JC, Sanchez del Pozo J, Marti Herreros M, Simon R, Maties M, Martin Hernandez E, Hennet T, Briones P 2004 Congenital disorder of glycosylation (CDG) type Ie. A new patient. J Inherit Metab Dis 27:591-600

16. Clayton P, Winchester B, Di Tomaso E, Young E, Keir G, Rodeck C 1993 Carbohydrate-deficient glycoprotein syndrome: normal glycosylation in the fetus. Lancet 341:956

17. Yuasa I, Ohno K, Hashimoto K, Iijima K, Yamashita K, Takeshita K 1995 Carbohydrate-deficient glycoprotein syndrome: electrophoretic study of multiple serum glycoproteins. Brain Dev 17:13-19

18. Peterson CB, Blackburn MN 1985 Isolation and characterization of an antithrombin III variant with reduced carbohydrate content and enhanced heparin binding. J Biol Chem 260:610-615

19. Malek A, Sager R, Lang AB, Schneider H 1997 Protein transport across the in vitro perfused human placenta. Am J Reprod Immunol 38:263-271

20. Gitlin D, Gitlin J 1975 Fetal and Neonatal Development of Human Plasma Proteins. Academic Press, New York, pp 263-319

21. Srai SK, Bomford A, McArdle HJ 2002 Iron transport across cell membranes: molecular understanding of duodenal and placental iron uptake. Best Pract Res Clin Haematol 15:243-259

22. Malek A, Sager R, Kuhn P, Nicolaides KH, Schneider H 1996 Evolution of maternofetal transport of immunoglobulins during human pregnancy. Am J Reprod Immunol 36:248-255

23. Malek A, Sager R, Schneider H 1998 Transport of proteins across the human placenta. Am J Reprod Immunol 40:347-351

24. Uehara K, Thelu J 2001 Stage- and tissue-specific expression of a beta-1,4galactosyltransferase in the embryonic epidermis. In Vitro Cell Dev Biol Anim 37:613-617

25. Zhou D, Chen C, Jiang S, Shen Z, Chi Z, Gu J 1998 Expression of $\beta 1,4$ galactosyltransferase in the development of mouse brain. Biochim Biophys Acta 1425:204-208

26. Granovsky M, Fode C, Warren CE, Campbell RM, Marth JD, Pierce M, Fregien N, Dennis JW 1995 GlcNAc-transferase V and core 2 GlcNAc-transferase expression in the developing mouse embryo. Glycobiology 5:797-806

27. de Jong G, van Eijk HG 1989 Functional properties of the carbohydrate moiety of human transferrin. Int J Biochem 21:253-263

28. de Jong G, van Noort WL, Feelders RA, de Jeu-Jaspars CM, van Eijk HG 1992 Adaptation of transferrin protein and glycan synthesis. Clin Chim Acta 212:27-45

29. Medvedova L, Knopp J, Farkas R 2003 Steroid regulation of terminal protein glycosyltransferase genes: molecular and functional homologies within sialyltransferase and fucosyltransferase families. Endocr Regul 37:203-210 